\title{
VISITOR BEHAVIOR AT THEME PARKS AS AN URBAN TOURISM IN THE CITY OF BANDUNG, INDONESIA
}

\author{
Ersy Ervina, Vany Octaviany. \\ Telkom University \\ ersy@tass.telkomuniveristy.acid, vany@tass.telkomuniversity.ac.id
}

\begin{abstract}
The presence of a variety of theme parks in Bandung, Indonesia is intended as an urban tourism and public green spaces whereby the townspeople can make interactions. In reality, there are many visitors who still not realize the purpose and function of the theme parks. Some of the newly constructed parks are damaged by visitor behavior. This condition makes the theme park less comfortable. This study was aimed to identify and analyze of visitor behavior at the Bandung theme parks as urban tourism.This study used quantitative descriptive analysis technique by tabulating the frequency responses of respondents. Visitor behavior was analyzed using two (2) sub variables, including personal and interpersonal factors. Personal factors consist of six indicators, i.e. (1) need, want and motivation; (2) perception; (3) learning; (4) personality; (5) lifestyle; and (6) self-concept. Meanwhile, interpersonal factors consist of five indicators, i.e. (1) culture; (2) reference group; (3) social class; (4) opinion leader; and (5) family. The analysis results show that the visitor behavior at theme parks as urban tourism, analyzed by personal and interpersonal factors, is in sufficient condition (not yet positive). On the personal factors, the highest indicator is need, want and motivation and the lowest indicator is personality. On interpersonal factors, the highest indicator is opinion leader. Therefore, it is necessary to enhance socialization in order to increase the knowledge of visitors pertaining to the function of theme parks and to amke proper regulations regarding superintendence of theme parks.
\end{abstract}

Keywords: Visitor Behavior, Theme Park, Urban Tourism, Bandung,

\section{Introduction}

The presence of theme parks pioneered by the Mayor of Bandung Mr. Ridwan Kamil is an alternative choice of cheap and festive parks for the city residents. The theme parks utilize parks as green open spaces that already exist in the city and packed in such a way with specific themes to appeal to visitors and as a means of public interaction between visitors and city residents.

The themes parks include Taman Jomblo, Taman Lansia, Taman Fotografi, Taman Film, Taman Pustaka Bunga, Taman Musik, Taman Binatang Peliharaan (Pet Park), Taman Vanda and Taman Super Hero, and Taman Alun- 
alun. From these parks, only a few parks are well known and always crowded, while some other parks tend to have a few visitors. For example, Taman Alunalun which has a strategic location, i.e. close to the city center, is always crowded.

There are a lot of things affecting the behavior of visitors of theme parks. It is certainly inseparable from the visitors' behaviors like motivation, interest, perception, lifestyle and cultural factor and reference. In addition, it is related to personal and interpersonal factors. Personal factors include the characteristics of each individual or hobby, while interpersonal factors include everything from outside of the individuals. The interpersonal factors, among others, come from relatives, reference, culture, and demography.

Some parks which are newly built and renovated suffer from damage, i.e. Taman Film is damaged because of visitors' bad behaviors and a park in Causeway Dago which suffers from vandalism. Based on the phenomena, this study was aimed at exploring more about visitor behavior, especially personal and interpersonal factors.

\section{Literature Review \\ Urban Tourism}

Urban tourism is a term for tourism in urban areas or cities. Shaw and William in Craggs (2008: 28) states that urban tourism is an area or region which deserves the potential to become attractive tourist destinations for local tourists, domestic and international visitors. Urban tourism planning should consider aspects of the visitors' needs. Cities have an important role for the realization of a local tourism. Cities are a place that provides all fulfillment of tourism needs, ranging from arrival, accommodation to facilities and infrastructure. Inskeep (1991: 236) describes the importance of city as follows:

"tourism may be very important in towns and cities, and in terms of tourist arrival, extent of accommodation and visit to tourist attraction features, may exceed the use of designated tourist resort."

Therefore, a city should offer a variety of attraction for the visitors. Some examples include museum, shopping areas, parks, and places to eat. This is in line with the statement of Inskeep (1991: 236):

"in addition to serving as gateway and staging areas to region or country, cities offer wide range of attraction in themselves, including museums, parks, theater, historic places, significant modern building, shopping, dining, entertainment and the overall urban ambience and cityscapes view".

\section{Visitor Attraction}

Visitor attraction is everything that has appeal for visitors. Some literature more likely to use visitor attraction than tourist attraction because "most visitors are not tourists, but residents or day trippers" (Swabrooke in Nowacki, 2015:11).

Swarbrooke (1996: 279) describes four major types of visitor attraction as follows: (1) natural feature, (2) man-made phenomena, (3) man-made phenomena special designed to attract visitor, and (4) special event and festival.

\section{Urban Green Space \& Theme Park}

Urban green space is a term which includes parks, parks, open corridors and wooded walking areas and constitute a key element of modern urban design 
(Bennet and Mulongoy, in Adinolfo, 2014: 534). There are two functions of the green spaces, including intrinsic and extrinsic functions.

a. Intrinsic functions

Green spaces have ecological functions, i.e. to ensure the sustainability of the physical area of a city. It should be one form which is located, sized and shaped certainly in an area of a city, such as green space for the protection of supporting resources of human life and for building a network of wildlife habitat.

b. Extrinsic functions

Green spaces have social, economic, architectural functions, i.e. to support and improve quality of the environmental and cultural value of a city, so it can be located and shaped according to its needs and interests, such as for beauty, recreation, and city's supporting architecture (Dep PU, 2013: 3).

Theme park is a park that carries a specific theme. According to Inskeep (1991: 86) theme parks are:

"oriented to particular themes, such as history, adventure, unusual geografic places, fantasy and futurism, or a combination of these in one park, and offer simulated experiences, show, thrill ride, shopping and variety of restaurant and snack bar in clean and controlled environment".

Viewed from the perspective of tourism, theme park is a special type of attraction. There are several types of tourist attraction, including natural, cultural, features, which are created artificially such as theme parks or amusement park and circus (Inskeep 1991: 85).

\section{Visitor Behavior}

Visitors are consumers or customers of tourism attractions. According to Morrison (2010: 98), Customer behavior is the way customer select, use and behave before and after they have purchased hospitality and travel services.

There are two factors that affect consumer behavior, namely personal and interpersonal factors. Both of these factors can be seen in Figure 1 below:

Figure 1. Factors Affecting Consumer Behavior

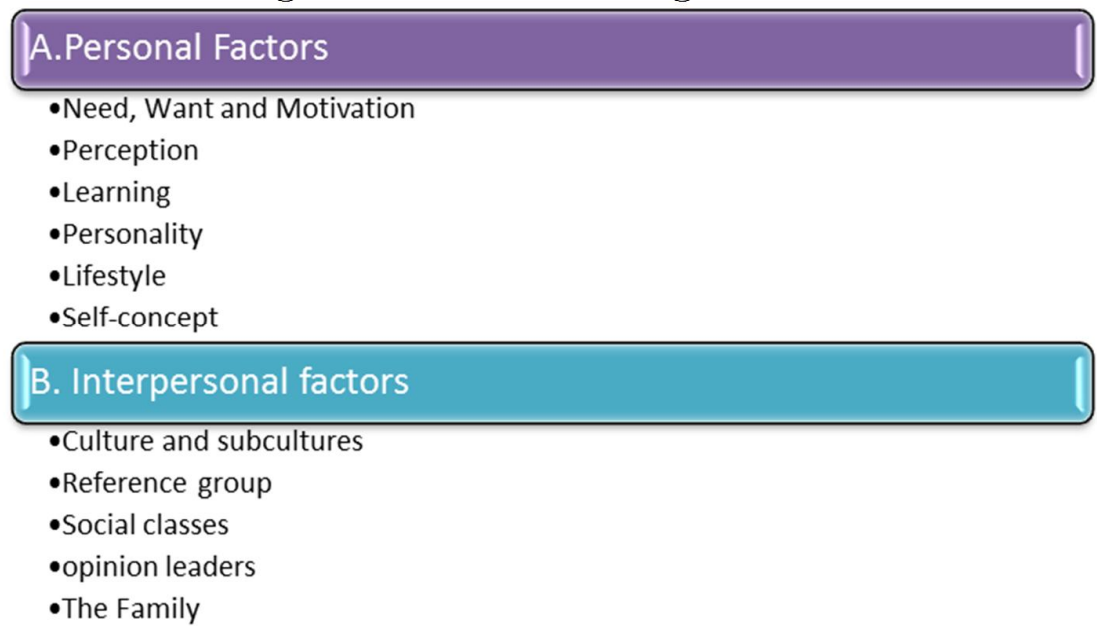

Source: Morrison (2010: 99) 


\section{a. Personal factors}

1) Need, want and Motivation.

Need implies fundamental needs of visitors such as comfort and safety when there is a gap between what they have and what they want to have. Want is a special way of visitors to consume something to satisfy their needs. Motivation is things necessary to know as the foundation of visitors to be aware of their needs.

2) Perception

Visitors use five senses, including seeing, hearing, tasting, touching and smelling. Perception is a cognitive impression which is a form of reality of individuals who influence their actions and behaviors towards an object.

3) Learning

We are more are more likely to learn from little things we do. Usually people adjust behavior patterns after learning from their experiences.

4) Personality

Visitors' personality is a combination of previous three factors. There is a motivation in personality, perception, learning and emotion.

5) Lifestyle

Lifestyle is the way or style of a person or in spending his/her life. The way we live is a function of activities, interests and opinions. This is reflected in everyday actions and the ways of filling leisure time.

6) Self-concept

Self-concept is a mental picture which consists of four different elements, including real self, ideal self, reference group, and self-image. Sirgy \& Malhotra (1982) explains that self-concept has a relationship with the way consumers choose products related to their personality, later called selfcongruity. In the world of tourism, self-congruity helps in knowing the motives of visitors in cultural-related events (Shon \& Yuan, 2011). As part of consumer behavior, self-concept gets a little attention from researchers although it may be a potential in making tourism experience (Todd, 2001). Todd further explains that self-concept can be the basis for a segmentation alternative.

\section{b. Interpersonal factors}

1) Culture and Subcultures

Culture is a combination of beliefs, values, attitudes, habits and traditions and patterns of behavior that are given by a particular person or group.

2) Reference Group

There are two types of reference, namely (a) primary groups including relatives members and friends where they can exist without any direct prohibition to interact; (b) secondary groups which are those who are in religious and job group, and paid membership (such as hobbies community, country clubs, and professional associations).

3) Social Classes

Social classes are relatively permanent and homogeneous. They are usually formed in an association. This association shares the same things like values, lifestyle, hobbies, status, education, and economic position. Social classes can usually be classified as upper, middle and lower. 
4) Opinion Leaders.

Leaders act as an information center for all members. Leaders share trends by seeking for information or using a product or a particular object before its members.

5) Family

Relatives is considered a factor that is strong enough to influence the behavior of consumers/visitors in selecting an object.

\section{Methodology}

Research Design

This study used a descriptive quantitative method. Descriptive research is a research which seeks to collect data, analyze data critically and draw a conclusion based on the facts at the time of the research. A descriptive study may be intended to examine humans in groups or individuals, a set of conditions, or an object or anything (Sugiama, 2008:37). Humans as individuals in this study were the theme park visitors. Quantitative method is used to help entrepreneurs in the business world, including in the decision making of tourism businesses. Such decisions may relate to optimization, estimation, identification, and correlation of problems (Bandesa in Utama \& Mahadewi, 2012: 125).

\section{Data collection technique}

The primary data collection in this study was done by distributing questionnaires to visitors of theme parks in Bandung. Observation and documentation were also conducted to support the core data. The abundant number of visitors to theme parks in Bandung made the population unable to be known exactly (infinite population). According to Zainudin (1998:101), when the proportion of population is not known with certainty, then the value of $p$ is considered $=0.5$. So, the sample calculation is as follows:

$$
\begin{aligned}
& n=\frac{z^{2} a \cdot p \cdot q}{d^{2}} \\
& n=\frac{(1,976)^{2}(0,5) \cdot(0,5)}{(0,10)^{2}}=97.5
\end{aligned}
$$

So, the number of samples in this study was 100 respondents.

\section{Results and Discussion}

\section{Overview of Theme Parks in the City of Bandung}

a. Taman Alun-Alun

Strategically, this park is located in the city center, i.e. the town square (AlunAlun) of the city of Bandung and adjacent to the Great Mosque. It has a quite vast area of artificial green grass, which makes it convenient for the city residents to do activities such as playing with relatives.

b. Taman Lansia

This park is located at Cilaki, Bandung. It is called Taman Lansia (Elderly Park) for its visitors are dominated by elderly who take exercise at this park. It is equipped with cobbled streets to be used as a therapy or reflection facilities.

c. Taman Jomblo 
Taman Jomblo, formerly known as Taman Cikapayang, is located in Dago area or Jalan. Ir H. Juanda. This park is often visited by young people to gather.

d. Taman Film

This park utilizes spaces under the Pasopati Flyover with an area of about 700 $\mathrm{m}^{2}$. It is intended as a means of citizens in the city to watch a show or movie. The park is equipped with a large TV or Megatron and chairs made like an amphitheater with seating that can accommodate approximately 500 people.

e. Taman Musik Centrum

The park is located at Jalan Belitung, exactly next to SMU 3 \& 5 Bandung. The goal is to accommodate the residents, especially the youths to practice or perform their hobbies of music, art and sport.

f. Taman Vanda

This park is located right in front of Bank Indonesia Old Buildings, or in the center of downtown (Jalan Merdeka). The park is adjacent to City Hall, making it very easy to find. It is equipped with fountains, and, at night, decorated with ornamental lights.

g. Taman Fotografi

The park is intended to accommodate the photography lovers. In this park, there are several works of photography. The park is located at Jalan Angrek (RE. Martdinata). In the past, it was called Taman Cempaka.

h. Taman Pustaka Bunga

This park is located at Jalan Cilaki. Pustaka Bunga, literally means Library of Flower, is intended as a display of a wide variety of flowers.

i. Taman Super Hero

This park is located at Jalan Cihapit with an area of $600 \mathrm{~m}^{2}$. In this park, there are several statues of famous superheroes who become idols of children like Gatot Kaca, Spiderman, Batman and others. Amenities at the park include a library and toilet.

\section{Distribution of the Theme Park Visitors}

The results of data analysis show that of nine theme parks, Taman AlunAlun is the most visited one. Following is the distribution of visitors of theme parks, which were taken from 100 respondents.

- Visitors age

Theme park visitors are dominated by students with an age range of 10-19 years (45\%). The second is an age range of 20-29 years (39\%), and the lowest is an age range of $40-49$ years (4\%) of the total number of respondents. 
Figure 2. Visitors age

Usia Pengunjung
$\square 10-19$ tahun $\square 20-29$ tahun $\square 30-39$ tahun
$\square 40-49$ tahun $\square>50$ tahun
$12 \%$

\section{- Visitors education}

The majority of visitors earn high school and diploma degree. The students are usually joined in particular communities or groups by utilizing theme parks as a means to gather.

\section{Figure 3. Visitors education}

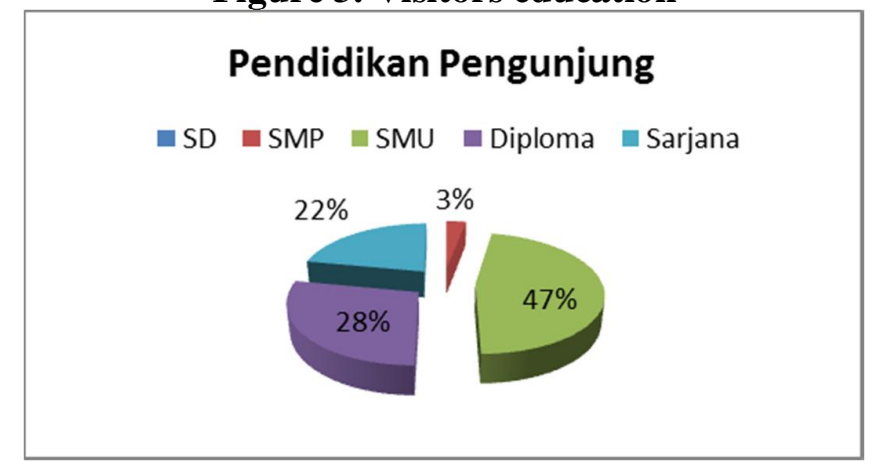

- Types of jobs

Jobs visitors are students with a percentage of $80 \%$, while professionals are the lowest (5\%).

Figure 4. Types of jobs

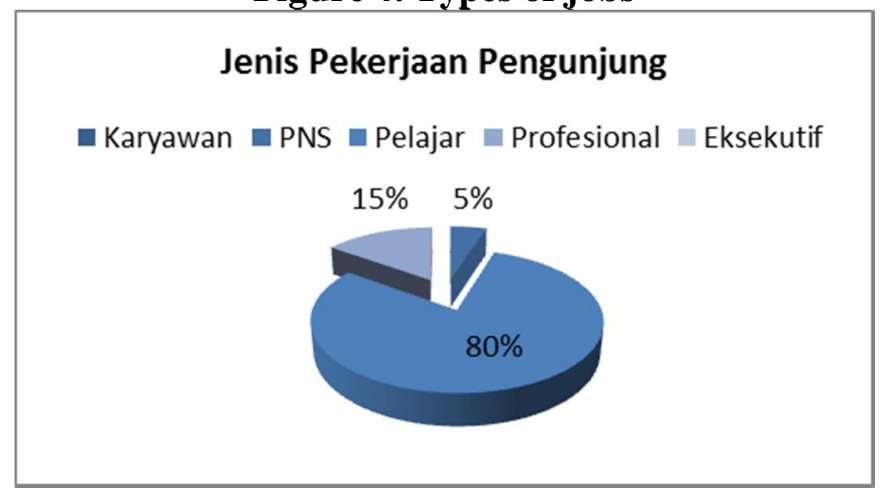

- Frequency of Visits

In term of the frequency of visits to the theme parks, it is known that $40 \%$ of respondents have visited the theme parks more than 3 times. There are quite a lot 
of theme parks in Bandung easier that the residents are easy to access them. Most of them are regular visitors.

Figure 5. Frequency of Visits

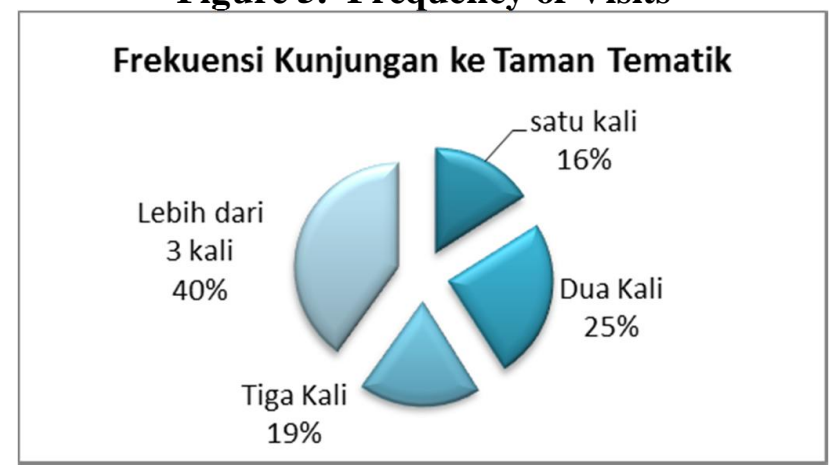

- Visit Purposes

Most visitors visit theme parks for relaxation (55\%). Relaxation activities include enjoying the atmosphere of the parks and exercise. There are $22 \%$ who visit theme parks to visit friends or relatives (VFR).

Figure 6. Visit Purposes

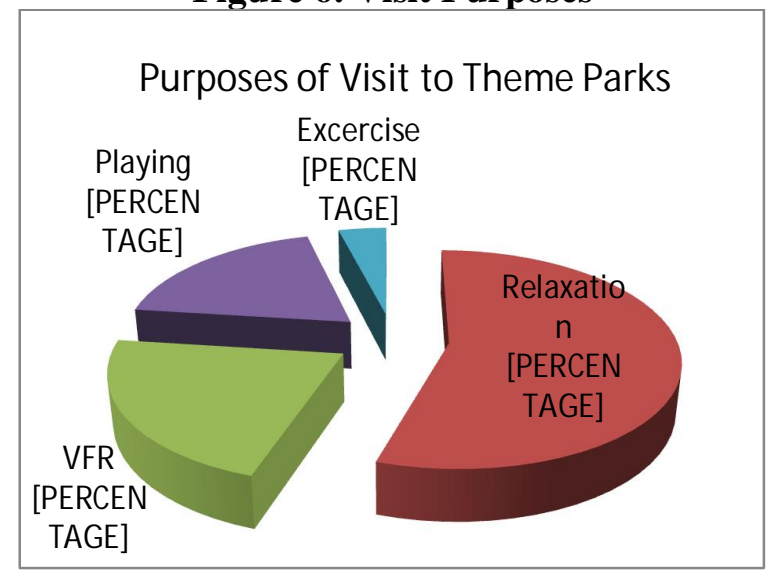

- Sources of Information

Visitors obtain information on theme parks from various sources. Most get such information from the internet $(53 \%)$, followed by from the printed media $(22 \%)$, and from friends or relatives in Bandung (19\%). 
Figure 7. Sources of Information

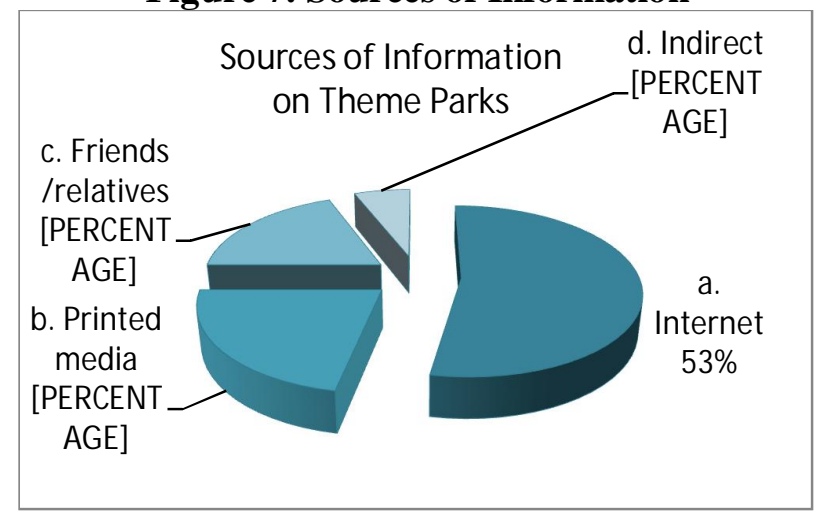

- Mode of Transportation

The educational backgrounds and occupations of the visitors, who are mostly students, affect the transportation mode used. Most of them use motorcycles (47\%).

Figure 8. Mode of Transportation

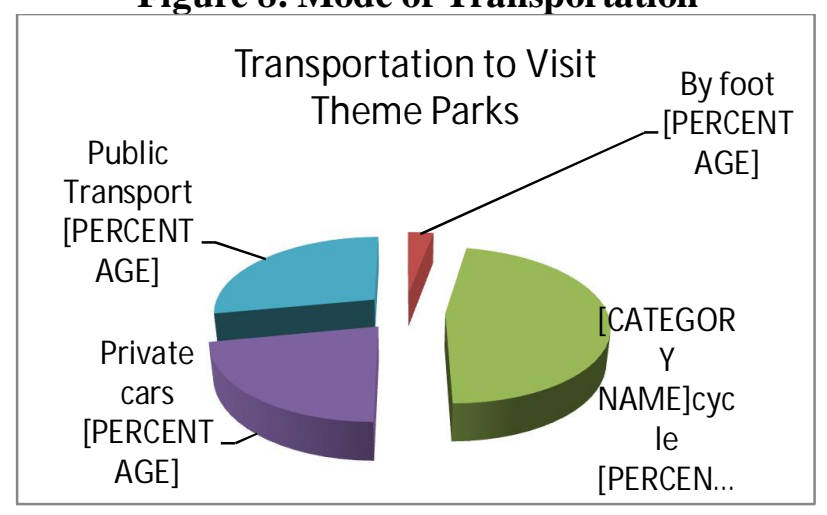

\section{Analysis of the Visitor Behavior on the Theme Parks}

\section{a. Personal Factors}

The analysis results show that personal factor is a factor which quite affects visitors in choosing theme parks as a means of urban tourism in the city of Bandung. This is shown by an average value of 3.68. This value means that personal factor contributes more than enough in affecting visitor behavior on theme parks as a means of urban tourism in the city of Bandung. Six indicators of personal factors examined include: (1) need, want \& motivation; (2) perception; (3) learning; (4) personality; (5) lifestyle and (6) self-concept. A graph displaying personal factors is presented as follows: 
Figure 9. Personal Factors

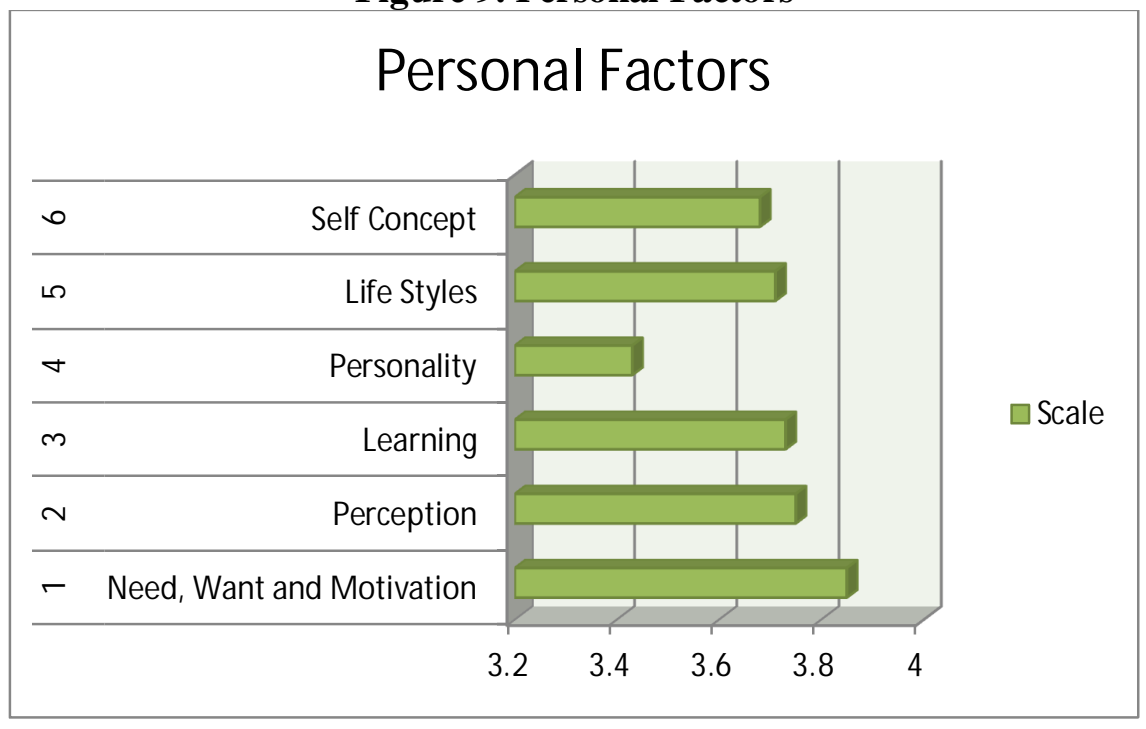

Based on Figure 8, it can be seen that indicator which has the highest contribution to personal factors is need, want and motivation visitors (3.85). This factor indicates that the presence of theme parks has been satisfying the needs and wants of the citizens of Bandung such as safety and comfort of the parks. The diversity of the parks, coupled with a theme of hobbies lead the townspeople to visit the parks, especially the students.

Indicator of perception has a value of 3.75, meaning that the image of theme parks already matches the townspeople's minds. Similarly, the means of learning shows that visiting the theme parks have stimulated ideas through the themes and atmosphere obtained in theme parks. This is evidenced from an average value of 3.73. This means that visitors agree that the theme parks serve as a means of learning.

The lowest personal factor is personality with an average value of 3.43 (moderate). As stated by Morrison, personality is a combination of previous three factors, i.e. need, want and motivation, perception and learning. It is closely associated with character and emotion of visitors. This implies that most visitors (students) have not been able to utilize the parks as where they should be. This can be seen with scattered trash around the parks, and even some facilities are damaged and suffers from vandalism.

Lifestyle is related to the ways visitors spend leisure time and do activities by visiting theme parks. This has a value of 3.71 , meaning that visiting theme parks is a part of the lifestyle of students. Theme parks are places to gather for particular communities.

Self-concept is a mental picture owned by visitors in choosing theme parks. It has a value of 3.68, meaning that the self-concept is in the category of not good, but more than enough. As argued by Sirgy, most of theme parks have described the concept of self-actualization of visitors' interest.

\section{b. Interpersonal factors}

Interpersonal factors are anything that determines the behavior of visitors of theme parks as a means of urban tourism which come from outside of 
visitors. There are five sub-factors studied, including 1) culture and subculture; 2) Reference group; 3) Social class; 4) Opinion leader and 5) family. The analysis results of visitors' interpersonal factors can be seen in Figure below:

Figure 10. Interpersonal Factors

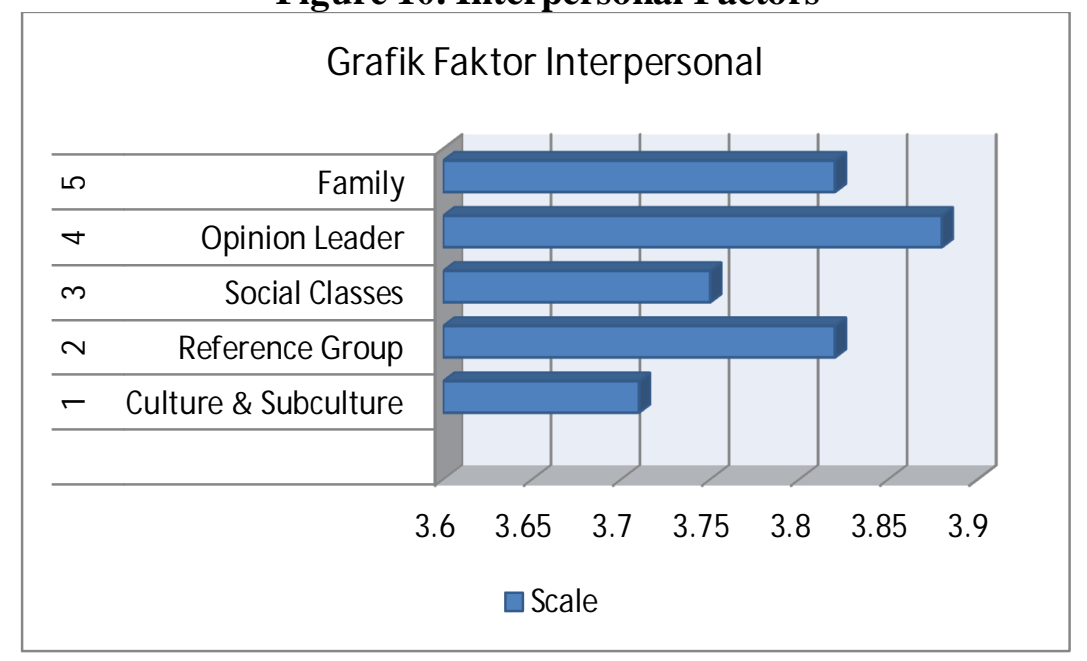

In average, interpersonal factors have a value of 3.79. This means that interpersonal factors of the theme park visitors have a high contribution to the visitor behavior. Of the five sub-factors, opinion leader occupies the highest value with 3.88, while cultural factor occupies the lowest value that affect interpersonal factors with an average score of 3.71 .

If we consider the majority of visitors who are the students, or members of particular communities, it is reasonable that leader opinion is at the highest position to be an interpersonal factor which plays a role in the visitor behavior. Similarly, reference group and family implies that students tend to follow the direction of teachers, community leaders as well as reference from their families in making use of theme parks as a means of urban tourism. In addition, most of the Bandung residents are at productive ages, so that approach employed to build theme parks is townspeople's activities or hobbies.

In case of cultural factor, currently, a lot of visitors does not know that the theme parks are a reflection of Sundanese culture. Only a few parks reflect Sundanese culture, while some other parks adopt modern themes like Taman Super Hero and Taman Musik. The analysis results show that 59\% of respondents agree that the existing theme parks have reflected the culture of the city of Bandung. This culture is formed from everyday life and activities of the townspeople. Therefore, the theme parks are visited by them to do activities.

\section{Conclusions}

1) Visitor behavior at theme parks has not shown significant positive value, which is evident from the results of the questionnaire responses and attitudes of respondents. Personal factors (need, want and motivation; perception; learning; personality; lifestyle; and self-concept) have an average value of 3.68. Meanwhile, interpersonal factors (culture; reference group; social class; opinion leader; and family) show an average value of 3.79. These two 
visitor behavior factors can be said 'quite good'. This is mostly reflected in the damaged facilities and scattered trash caused by visitors, but the existence of the theme parks is enough to give new fresh nuances for the townspeople of the city of Bandung.

2) The most dominant factor in the visitor behavior is interpersonal factor, in which it has an average value of 3.79. The highest interpersonal factor is opinion leader. Certain communities or organizations tend to take advantage of existing theme parks to socially interact with their members.

\section{Recommendations}

It is necessary to improve personal factors, specifically related to personality and self-concept. Personality forms habits of visitors who will ultimately shape their positive behaviors in visiting theme parks as a means of urban tourism. In addition, it is necessary to intensify the communication system and socialization in order to improve the visitors' knowledge related to functions and benefits of public open spaces. Theme park is not just a decoration but a means of townspeople to have leisure activities and make social interaction.

Bandung city government also needs to add signs or boards showing the location of city parks and facilities existing at the theme parks to make the townspeople easy to access and find out the theme parks and provide a positive added value for visitors. Moreover, there should be regulations to give sanctions against persons who damage the park facilities.

This study is limited to the visitor behavior. Therefore, to find out more about the interest of the townspeople of the city of Bandung in the theme parks, it need to be analyzed through their preferences in choosing theme parks in the city of Bandung. 